\title{
Influence of the solvent polarity and pH over the extraction of bisphenol A from samples of sanitary landfill leachate
}

\author{
N. C. Vieceli ${ }^{1}$, C. F. Gonzatti ${ }^{1}$, J. A. Marzotto ${ }^{1}$ \& I. N. Filho ${ }^{2}$ \\ ${ }^{I}$ Environmental Engineering Course, University of Caxias do Sul, \\ RS-Brazil \\ ${ }^{2}$ Center of Exact Sciences and Technology, \\ Institute of Environmental Sanitation, University of Caxias do Sul, \\ RS-Brazil
}

\begin{abstract}
In this work the influence of the solvent polarity and $\mathrm{pH}$ over the quantitative analysis of bisphenol A (BPA) in the leachate of a sanitary landfill was investigated. During five months, five samples of raw and treated leachate were collected and submitted to Solid Phase Extraction (SPE) with C-18 cartridges. The samples were extracted with and without lowering $\mathrm{pH}$ and with polar (ethanol) and non polar ( $n$-hexane) solvents. The instrumental analysis was performed by Gas Chromatography with Flame Ionization Detector (GC/FID). The samples extracted without acidification and alcoholic extract showed the highest amount of BPA. The maximum concentration of BPA in wastewaters is not ruled by the Brazilian laws. However, the BPA concentrations found in the present work were far above the recommendation of the USEPA (United States Environmental Protection Agency) for other well known endocrine disruptors such as di(2-ethylhexyl) phthalate.
\end{abstract}

Keywords: bisphenol A, SPE, gas chromatography, sanitary landfill, leachate.

\section{Introduction}

Bisphenol A (BPA), 4,4'-(1-methylethylidene) bisphenol, is widely employed as a monomer in the production of polycarbonate and some epoxy resins that are commonly employed as adhesives and cover materials (Yamamoto et al. [1]). 
BPA improves some physical properties of polymeric materials, such as resistance, hardness, and thermal stability.

BPA is an antioxidant highly resistant to chemical degradation and its environmental persistence may be due to the low vapor pressure and relatively low octanol-water partitioning coefficient. Under anaerobic conditions, BPA can be considered non biodegradable (Li et al. 2008)[2]. BPA can interact with humans and wildlife and cause adverse effects. Some examples of these adverse effects are the formation of additional female organs, enlarged accessory sex glands, morphological and functional gonadal dysfunction and interference in the functioning of the endocrine system (Forbes et al. [3], Nelson [4], Mantovani [5], Bauer and Hermann [6], Baird [7], Huang [8], Suzuki and Hattori [9].

The endocrine disrupting action of BPA is recognized by important environmental agencies such as USEPA (United States Environmental Protection Agency), UKEA (United Kingdom Environmental Agency) and JEA (Japan Environmental Agency) [10]. BPA is also readily absorbed by skin [11] and this rote must contribute substantially for the human exposition to the free BPA monomer. BPA was also detected in the urine of pregnant women working as cashiers and women that consume canned vegetables, at least once a day [12].

There are many studies reporting the evaluation of artificial endocrine disruptors in wastewaters (Wintgens et al. [13, 14], Fernandez et al. [15], Fauser et al. [16], Zheng et al. [17] and the extraction of BPA and plasticizers such as di- $n$-butylphathalate and di(2-ethylhexyl) phthalate from wastewaters using the acidification to enhance the extraction efficiency $[1,18,19]$. However, as far as we know, the investigation about the influence of the extraction conditions (such as $\mathrm{pH}$ and solvent polarity) over the amount of the detected contaminant is still lacking in the literature.

In order to study this influence, five landfill leachate samples were submitted to Solid Phase Extraction (SPE) with and without the acidification step with polar (ethanol) and non polar ( $n$-hexane) solvents. The instrumental analysis was performed by Gas Chromatography with Flame Ionization Detector (GC/FID).

\section{Methodology}

\subsection{SPE}

The SPE cartridges (Supelclean ${ }^{\mathrm{TM}}$ LC-18 $6 \mathrm{~mL}$, Sigma-Aldrich) were previously conditioned by the sequential elution of methanol $(5 \mathrm{~mL})$ and methylene chlorine $(5 \mathrm{~mL})$. After each elution the cartridges were vacuum dried for $10 \mathrm{~min}$. Finally, the cartridges were eluted with deionized water and vacuum dried for $20 \mathrm{~min}$.

\subsection{Standard solution of BPA}

Two standard solutions of BPA (purity $>99 \%$, Fmaia, São Paulo, Brazil) at $1000 \mathrm{mg} \mathrm{L}^{-1}$ were prepared with $n$-hexane and ethanol (Fmaia, São Paulo, Brazil). Hydrochloric acid was added to two aliquots of $100 \mathrm{~mL}$ of both 
solutions until $\mathrm{pH} \approx 2.0$. Other two aliquots of $100 \mathrm{~mL}$ were extracted without the acidification step, generating the extracts shown in Table 1.

The organic solvents were purified in glass apparatus. Extraction blanks were performed to evaluate the samples contamination by the laboratory environment. No BPA peaks were detected by GC/FID in the extraction blanks.

The real samples of landfill leachate were extracted according the best conditions (with or without acidification).

Table 1: Solvents and $\mathrm{pH}$ conditions and extracts nominations of the standard solutions extractions.

\begin{tabular}{ccc}
\hline $\mathrm{pH}$ & Solvent & Extract nomination \\
\hline Acidic & Ethanol & $\mathrm{A}-\mathrm{E}^{\mathrm{a}}$ \\
Acidic & $n$-hexane & $\mathrm{A}-\mathrm{H}^{\mathrm{b}}$ \\
Normal & Ethanol & $\mathrm{N}-\mathrm{E}^{\mathrm{c}}$ \\
Normal & $n$-hexane & $\mathrm{N}-\mathrm{H}^{\mathrm{d}}$ \\
\hline
\end{tabular}

${ }^{\mathrm{a}} \mathrm{A}-\mathrm{E}=$ acidified sample extracted with ethanol.

${ }^{\mathrm{b}} \mathrm{A}-\mathrm{H}=$ acidified sample extracted with $n$-hexane.

${ }^{\mathrm{c}} \mathrm{N}-\mathrm{E}=$ non acidified samples extracted with ethanol.

${ }^{\mathrm{d}} \mathrm{N}-\mathrm{H}=$ non acidified samples extracted with $n$-hexane.

\subsection{Instrumental analysis}

A PerkinElmer Gas Chromatograph model Autosystem XL, with Flame Ionization Detector was used for identification of BPA by comparison between the retention times of the BPA sample peak and the standard compound. The quantification was done by the internal normalization method. An Elite-5 fused silica capillary column $(30 \mathrm{~m} \times 0.25 \mathrm{~mm}$ i.d. crossbond 5\% diphenyl $-95 \%$ dimethyl polysiloxane, $0.25 \mu \mathrm{m}$ film thickness) was used for the GC separation using the following oven temperature program: $150{ }^{\circ} \mathrm{C}(5 \mathrm{~min}$ hold $)$ heating to $250{ }^{\circ} \mathrm{C}$ at $3{ }^{\circ} \mathrm{C} / \mathrm{min}$ and heating to $300{ }^{\circ} \mathrm{C}$ at $10{ }^{\circ} \mathrm{C} / \mathrm{min}$ (5 min hold). The injector temperature was $250^{\circ} \mathrm{C}$. The injection volume was $1.0 \mu \mathrm{L}(\mathrm{n}=3)$ in the split mode (1:50).

\subsection{Recovery grade and detection limit}

The recovery grades were measured by the extraction of real samples in the best condition (with or without acidification) spiked with a BPA standard solution $\left(20 \mu \mathrm{g} \mathrm{mL}^{-1}\right)$. The detection limit was evaluated by successive dilutions of a BPA standard solution $\left(100 \mu \mathrm{g} \mathrm{mL}^{-1}\right)$.

\section{Results and discussion}

The detection limit was $0.5 \mu \mathrm{g} \mathrm{mL} \mathrm{m}^{-1}$ and the detector response was linear between 0.5 and $25 \mu \mathrm{g} \mathrm{mL} \mathrm{m}^{-1}\left(\mathrm{R}^{2}=0.913\right.$; equation: $\left.\mathrm{y}=0.424 \mathrm{x}-0.078\right)$. The recovery grade was $98.73 \%( \pm 4.51)$. 
Figure 1 shows the concentrations of BPA in the standards solutions extracted with and without acidification and ethanol and $n$-hexane.

No BPA peaks were detected in the non acidified samples extracted with $n$ hexane (N-H). In this way, the bar is absent in Figure 1. The samples extracted with ethanol showed the highest recovery grade (A-E and N-E). The increase in the recovery grade promoted by the samples acidification was of $5.5 \%$ in the ethanol extracts. This result suggests that, if the ethanol concentration in the samples is higher than $0.1 \%$, the acidification procedure can be discarded from the sample handling procedures. It is well known that the excessive sample handling can introduce important quantitative errors by the analyte's lost. On the other hand, if the BPA concentration in the samples is below $0.1 \%$, the acidification process can improve the analyte's extraction.

The affinity between BPA and the ethanol phase can be explained by its chemical structure (Figure 2), the analyte's physical-chemical properties and the water and ethanol dipole moments.

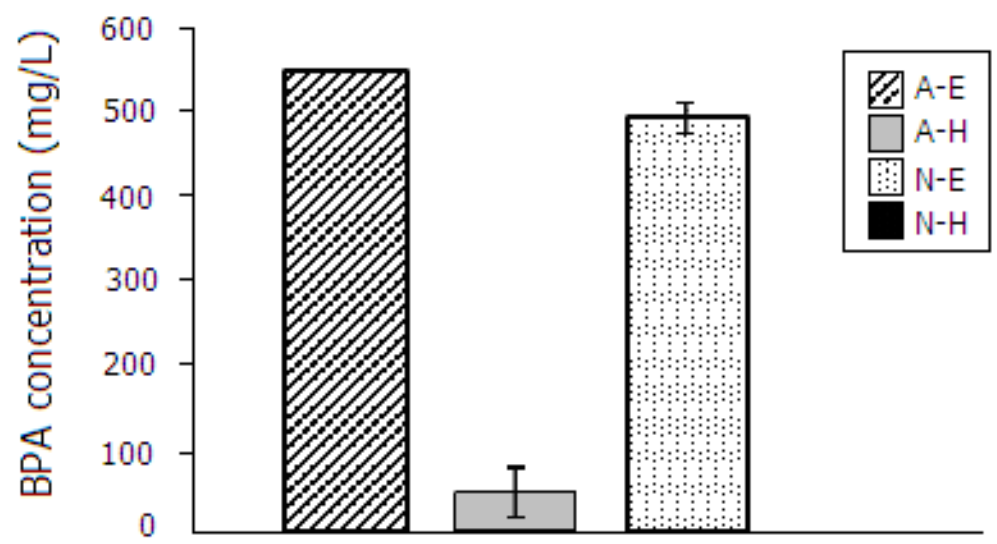

Figure 1: Influence of the standards solution $\mathrm{pH}$ and solvent polarity over the concentrations of BPA. The errors bars represent \pm standards deviations. A-E = acidified sample extracted with ethanol; $\mathrm{A}-\mathrm{H}=$ acidified sample extracted with $n$-hexane; N-E = non acidified samples extracted with ethanol; $\mathrm{N}-\mathrm{H}=$ non acidified samples extracted with $n$-hexane.<smiles>CC(C)(c1ccc(O)cc1)c1ccc(O)cc1</smiles>

Figure 2: $\quad$ BPA chemical structure. 
The BPA presents partition coefficient octanol-water (Log $K_{\text {Ow }}$ ) of 3.4 and water solubility between 120 and $300 \mathrm{mg} \mathrm{L}^{-1}$ [15]. The relative water solubility of BPA may be due to the two hydroxyl groups attached to the benzene rings. These hydroxyl groups can perform hydrogen bonds with the water molecules.

The sample acidification may break these hydrogen bonds because the acid may promote the strongest dipole interactions with water, due to the higher dipole moment of $\mathrm{HCl}$ (in relation to the BPA). In this way, the BPA molecules (free from the water hydrogen bonds) can migrate from the water phase to the stationary phase.

During the elution process, the ethanol hydroxyl groups may perform hydrogen bonds with the adsorbed BPA and release this compound from the stationary phase. The $n$-hexane is a non polar molecule without hydroxyl groups and desorbs less efficiently the BPA from the stationary phase. Figure 3 shows the acidification, adsorption and desorption equilibria of BPA.
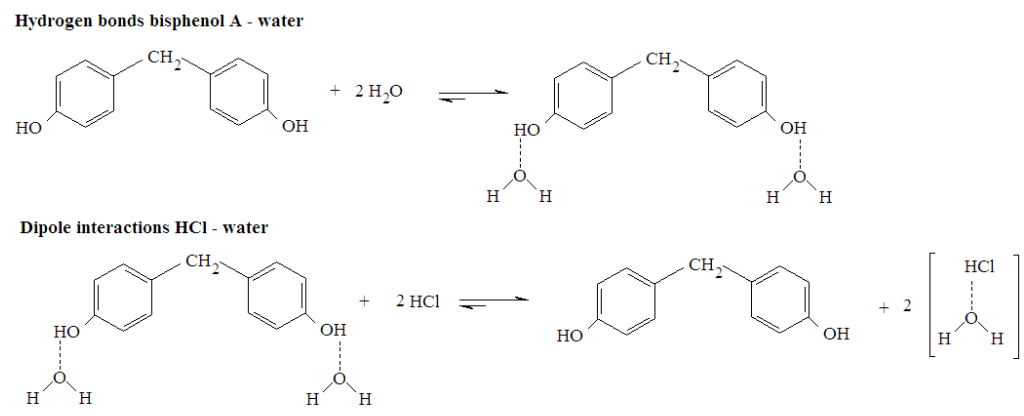

Bisphenol A adsorption

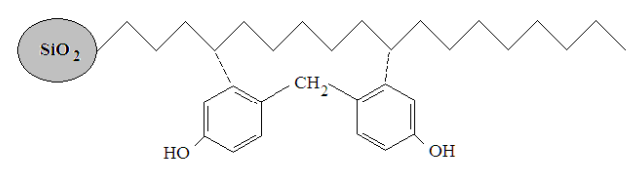

Bisphenol A release
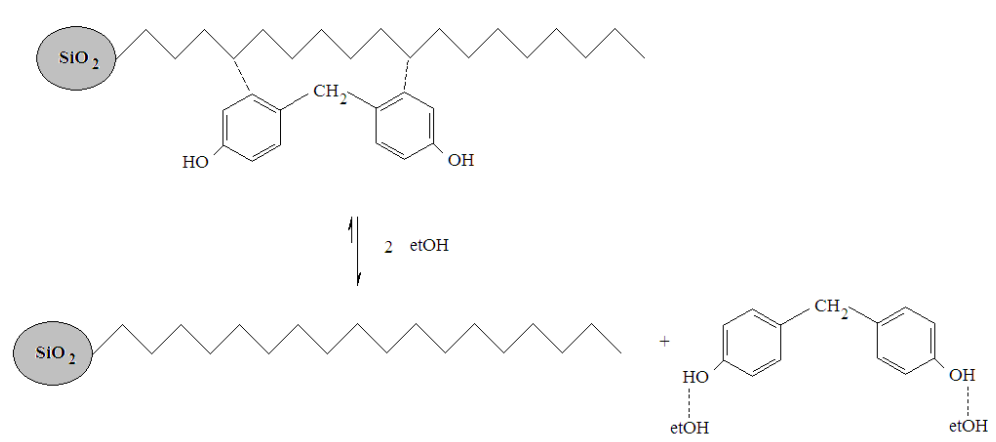

Figure 3: Acidification, adsorption and desorption equilibria of BPA. 
In order to access the effect of the solvent polarity and matrix effects in real samples over the amount of the extracted BPA, four $100 \mathrm{~mL}$ aliquots of raw and treated leachate (the leachate was treated by the wetlands technique), were extracted with ethanol and $n$-hexane (polarity index $=5.2$ and 0.06 , respectively). Those real samples were extracted in the same way that the standards solutions discussed above.

As can be seen in Figure 4 the average chromatographic peak areas of BPA extracted with ethanol were far above the ones extracted with $n$-hexane. The chromatographic area of the BPA extracted with $n$-hexane from the treated sample was below the limit of detection. In this way this bar isn't showed in Figure 4.

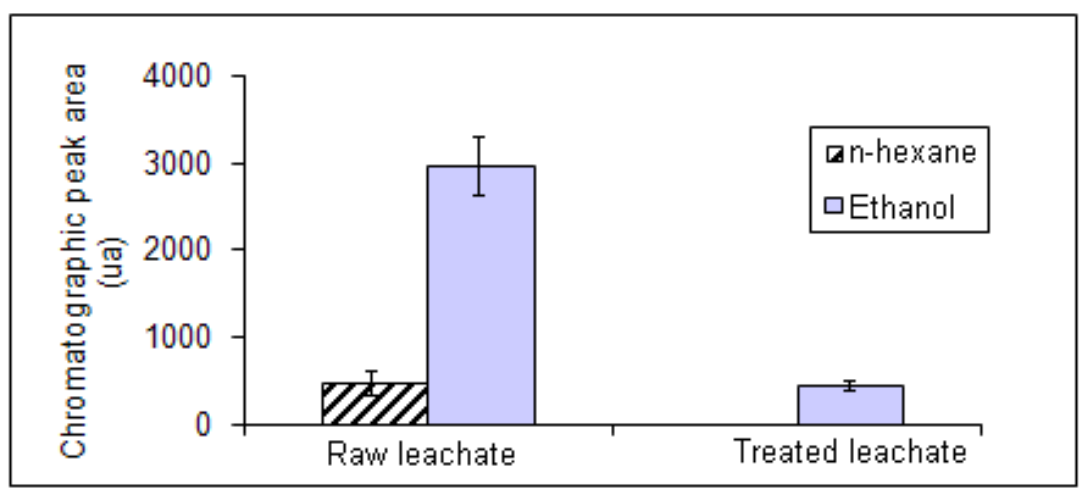

Figure 4: Influence of the solvent polarity over the extraction efficiency of BPA. The errors bars represent \pm standards deviations.

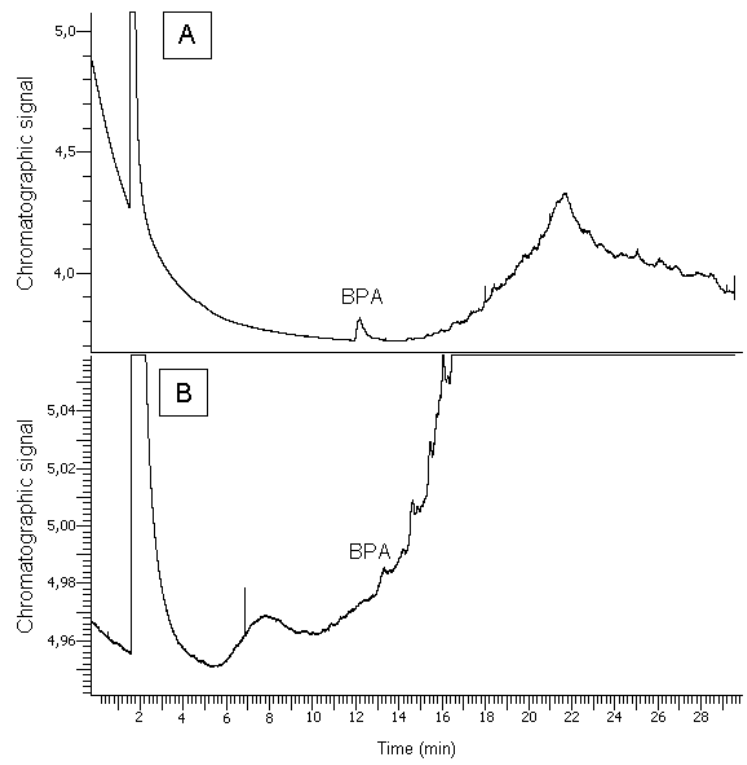

Figure 5: Chromatographic profiles of the BPA extract with ethanol (A) and $n$-hexane (B). 
Figure 5 shows the chromatographic profiles of the BPA extract with ethanol (A) and $n$-hexane (B).

\section{Conclusions}

The sample's acidification allows the formation of stable interactions (like hydrogen bonds) among the hydrochloric acid and water molecules. The BPA elution was favored when the cartridge was washed with a polar solvent (ethanol). In this procedure, the hydrogen bonds among the BPA and $\mathrm{HCl}$ molecules were favored.

The acidification allows the increase of $5 \%$ of the extraction efficiency. In this way, the acidification step is recommended for the quantification of BPA in samples where the concentration of this analyte is below $0.1 \%$. In these cases the acidification step may avoid important lost of the analyte and improve the detection limit in the instrumental analysis.

Our next step will be to evaluate the influence of the acidification step over the extraction yield of other endocrine disruptor like di(2-ethylhexyl) phthalate and di- $n$-butyl phthalate.

\section{Acknowledgements}

To the National Council of Research and Technological Development (CNPq) and University of Caxias do Sul.

\section{References}

[1] Yamamoto, T., Yasuhara, A., Shiraishi, H. \& Nakasugi, O., Bisphenol A in hazardous landfill leachates. Chemosphere, 42, pp. 415-418, 2001.

[2] Li, J., Zhou, B., Liu, Y., Yang, Q. \& Cai, W., Influence of the coexisting contaminants on bisphenol A sorption and desorption in soil. Journal of Hazardous Materials, 151, pp. 389-393, 2008.

[3] Forbes V.E., Selcka, H., Palmqvista, A., Aufderheide, J., Warbritton, R., Poundsc, R., Thompson, N., Hoeven, N. \& Caspers, N., Does bisphenol A induce superfeminization in Marisa Cornuarietis? Part I: Intra- and interlaboratory variability in test endpoints. Ecotoxicology and Environmental Safety, 66, pp. 309-318, 2007.

[4] Nelson, P., Epidemiology, biology, and endocrine disrupters. Occupational and Environmental Medicine, 60, pp. 541-542, 2003.

[5] Mantovani, A., Problems in testing and risk assessment of endocrine disrupting chemicals with regard to developmental toxicology. Chemosphere, 39, pp. 1293-1300, 1999.

[6] Bauer, M.J., \& Herrmann, R., Estimation of the environmental contamination by phthalic acid esters leaching from household wastes. Science of the Total Environment, 208, pp. 49-57, 1997. 
[7] Baird, C., Environmental Chemistry, Freeman and Company: New York, pp., 1999.

[8] Huang, Q.G.W.J.W., Transformation and removal of bisphenol A from aqueous phase via peroxidase-mediated oxidative coupling reactions: Efficiency, products and pathways. Environmental Science and Technology, 395, pp. 6029-6303, 2005.

[9] Suzuki N. \& Hattori, A., Bisphenol A suppresses osteoclastic and osteoblastic activities in the cultured scales of goldfish. Life Science, 73, pp. 2237-2247, 2003.

[10] Ghiselli, G. \& Jardim, W.F., Endocrine disruptors in the environment. Química Nova, 30(3), pp. 695-706, 2007. Title and abstract in English.

[11] Zalko, D., Jacques, C., Duplan, H., Bruel, S. \& Perdu, E., Viable skin efficiently absorbs and metabolizes bisphenol A. Chemosphere, 2010, doi:10.1016/j.chemosphere.2010.09.058.

[12] Braun, J.M., Kalkbrenner, A.E., Calafat, A.M., Bernert, J.T., Ye, X., Silva, M.J., Barr, D.B., Sathyanarayana, S., \& Lanphear, B.P., Variability and predictors of urinary bisphenol A concentrations during pregnancy. Environmental Health Perspectives, 2010, 131. doi: 10.1289/ehp.1002366.

[13] Wintgens. T., Gallenkemper M. \& Melin, T. Occurrence and removal of endocrine disrupters in landfill leachate treatment. Water Science and Technology, 48, pp. 127-134, 2003.

[14] Wintgens. T., Gallenkemper, M. \& Melin, T., Removal of endocrine disrupting compounds with membrane process in wastewater treatment and reuse. Water Science and Technology, 50, pp. 1-8, 2004.

[15] Fernandez, M.P., Noguerol, T., Lacorte, S., Buchanan, I. \& Piña, B., Toxicity identification fractionation of environmental estrogens in wastewater and sludge using gas and liquid chromatography coupled to mass spectrometry and recombinant yeast assay. Analytical and Bioanalytical Chemistry, 393, pp. 957-968, 2008.

[16] Fauser, P., Vikelsoe, J., Sorensen, P.B. \& Carlsen, L., Phthalates, nonylphenols and LAS in an alternately operated wastewater treatment plant - fate modelling based on measured concentrations in wastewater and sludge. Water Research, 37, pp. 1288-1295, 2003.

[17] Zheng, Z., He, P., Shao, L, \& Lee, D., Phthalic esters in dissolved fractions of landfill leachates. Water Research, 41, pp. 4696-4702, 2007.

[18] Azevedo, D.A., Lacorte, S., Viana, P. \& Barceló, D., Occurrence of nonylphenol and bisphenol-A in surface waters from Portugal. Journal of the Brazilian Chemical Society, 12(4), pp. 532-537, 2001.

[19] Marttinen, S.K., Kettunen, R.H., Sormunen, K.M. \& Rintala, J.A., Removal of bis(2-ethylhexyl) phthalate at a sewage treatment plant. Water Research, 37(6), pp. 1385-1393, 2003. 